\title{
A coordination theoretic model for three level supply chains using contracts
}

\author{
ARSHINDER $^{1}$, ARUN KANDA $^{2}$ and S G DESHMUKH ${ }^{*, 2}$ \\ ${ }^{1}$ Department of Management Studies, Indian Institute of Technology Madras, \\ Chennai 600036 \\ ${ }^{2}$ Department of Mechanical Engineering, Indian Institute of Technology Delhi, \\ New Delhi 110016 \\ arshinder@iitm.ac.in; akanda@mech.iitd.ernet.in; deshmukh@mech.iitd.ernet.in
}

MS received 20 November 2007; revised 19 May 2009

\begin{abstract}
Typically, supply chain members are dependent on each other to manage various resources and information. The conflicting objectives and lack of coordination between supply chain members may often cause uncertainties in supply and demand. The basic elements of coordination theory like interdependency, coherency and mutuality may help in effective flow of information and material between the dependent supply chain members. Supply chain contract can be an effective coordination mechanism to motivate all the members to be a part of the entire supply chain. There are different types of supply chain contracts such as buy back and quantity flexibility contracts. Supply chain performance may be substantially improved by properly designing the contracts to share risks and rewards. The objective of this paper is to explore the applicability of coordination elements through an analytical model in three-level (Manufacturer-distributorretailer) serial supply chains using contracts. The model evaluates the impact of supply chain contracts on various performance measures. The impact of some contract may be on some specific performance measure only, which helps managers to choose the type of contract if there is an objective of improving certain performance measure before hand. In three-level supply chains, the contracts are designed at two distinct interfaces: Manufacturer-distributor and distributor-retailer. The model demonstrates the complexity in evaluating the decision variables of three level supply chains. The proposed model is a novel approach to apply coordination theory at various levels of supply chain. The model also presents how the coordination elements are related to each other in various coordination cases.
\end{abstract}

Keywords. Supply chain contracts; coordination; buy-back; quantity flexibility; interdependency; mutuality.

*For correspondence 


\section{Introduction}

The biggest challenge in the supply chain (SC) is to manage disparate but dependent members of the supply chain. For an efficient supply chain, it is expected from all the supply chain members that they behave coherently to achieve supply chain coordination. The centralized control of supply chain assures channel coordination but it may not be realistic. In decentralized control, the supply chain members optimize local decisions without consideration of the impact of their decision on the other member's performance and on the overall performance of the supply chain (Whang 1995). By looking at the problems of managing relationships between the supply chain members in a complex SC network, a need arises to tackle this problem using coordination theory.

In any system the smooth functioning of entities is the result of well-coordinated entities. However, it may be very difficult to define 'coordination' precisely. There is no unique perspective on coordination, but the lack of coordination can be easily articulated through a variety of surrogate measures. The coordination can be viewed from different perspectives, for example: based on organization structure (Mintzberg 1979), coordination theory (Malone \& Crowston 1994), work group coordination theory (Chaudhary et al 1996), and distributed artificial intelligence theory (Chaib-Draa et al 2004). The most commonly accepted definition is from the literature of coordination theory 'Coordination can be defined as an act of managing dependencies between entities and the joint effort of entities working together towards mutually defined goals' (Malone \& Crowston 1994). The study of coordination theory in different disciplines like organization theory, action coordination, sociology and psychology, resource sharing and distributed artificial intelligence may give different connotations attached with coordination. Recently, the application of coordination can also be seen in the supply chain. According to Simatupang et al (2002), coordination is a prerequisite to achieve the mutual goal of the supply chain as a whole, as well as those of the participating units, given the nature of interdependencies between these units.

From the definitions and different models of coordination (Arshinder et al 2008), it can be observed that coordination constitutes identifying different interdependent activities to answer the following posers: How are these activities dependent? Who performs these activities? How to manage those interdependencies between activities? How are plans specified and standardized towards common goals?

Typically, the supply chain members are dependent on each other for resources and information and these members need to be coordinated by efficiently managing dependencies between each other (Arshinder et al 2006). Hence, a coordination mechanism is necessary, which motivates the members taking local decisions to pursue supply chain coordination (SCC). Supply chain coordination can be achieved with joint decision making of all processes of the supply chain: procurement, production, distribution and warehousing and economic allocation of the requirement of resources among supply chain members (Kim et al 2005). The coordination perspective may motivate the supply chain members to work coherently by identifying inter-dependencies between each other thereby mutually defining goals and sharing risks and rewards. Hence, coherency and mutuality (defined in the following sections) can act as driving elements to achieve coordination, which have been explored and applied in the presented model in this paper.

It is difficult to measure coordination in the supply chain, but the importance of coordination needs to be stressed. An analytical model, which may demonstrate the utility of coordination mechanism by improving relevant performance measures, may be of use to practitioners. Supply chain contracts are useful tools to make the several supply chain actors of a 
decentralized setting behave coherently and in a coordinated manner. The basis of contract model has originated from the classical newsboy problem (Atkinson 1979). The classical newsboy problem is a single period model applied to seasonal products. The objective of newsboy model is to determine the optimal order quantity by setting marginal revenues equal to marginal costs. There are various extensions of newsboy model discussed in the literature with major focus on two-level supply chain with expected profits as the performance measure (Nahmias \& Smith 1994 and Yang et al 2007).

Since a supply chain is a network with multiple organizations with complex interdependencies, coordination theory is applicable to it. To view supply chain as a big system and the consideration of interests of the supply chain members all taken together adds difficulty to coordinate supply chain members. In the present paper, the contracts have been analysed in three-level serial supply chain for single period model to explore the importance and complexity of coordination.

\section{Supply chain contracts}

A contract can be defined as an agreement between two parties. Supply chain contract is the set of many clauses that offers suitable information and incentive mechanism to guarantee all the firms in the SC to achieve coordination and optimize the channel performance (Cachon 2004). Supply chain contracts formally rule the transactions between the supply chain actors and later utilize incentives (risks and rewards) to make the SC member's decisions coherent among each other. Generally, the contracts analysis offers guidance in negotiating the terms of the relationship between supplier and buyer. The contracts are designed to sort out conflicts that may crop up in future. The supply chain contracts may be price-based contracts (buyback contracts) or quantity based contracts (quantity flexibility contracts) as discussed below:

\subsection{Buyback contract}

In buyback contract, the buyer is allowed to return any leftover units to the supplier at the end of the period at some set buyback price. The buyback contract increases the order quantity of the buyer as the contract increases the salvage value per unit for the buyer. The rationale for returns policies may link with the insurance.

Pasternack (1985) developed a single period hierarchical model considering pricing decision faced by the manufacturer to examine possible pricing and return policies. The model demonstrated that a policy whereby a manufacturer offers retailer full credit for a partial return of goods might achieve channel coordination, whereas, in a multi-retailer environment, a pricing and return policy in which a manufacturer offers retailers a partial credit for all unsold goods can achieve channel coordination. Padmanabhan \& Png (1997) studied the impact of two factors: retail competition and demand uncertainty on the manufacturer's decision to accept or reject returns. The manufacturer will be benefited from the returns policy when the production costs are sufficiently low and demand uncertainty is not too great. Emmons \& Gilbert (1998) studied the role of returns policy with full or partial refund for unsold goods. A multiplicative model of price dependent demand uncertainty was proposed, which presented maximization of total profits of the manufacturer and the retailer with returns policy.

Krishnan et al (2004) have analysed that buyback contract coupled with promotional cost sharing agreements between manufacturer and retailer result in supply chain coordination. The other consideration in buyback contract is the case of information sharing and asymmetrical information between the supply chain members (Yao et al 2005 and Yue \& Ranganathan 2007). 
Bose \& Anand (2007) proposed that by assuming transfer price exogenous the buyback contract is Pareto efficient. Yao et al (2008) proposed an analytical model to analyse the impact of stochastic and price dependent demand on returns policy between manufacturer and retailer.

The other variants of buyback contracts discussed in literature are: stochastic salvage capacity in fashion industry (Lee \& Rhee 2007); two period contract model in case of decentralized assembly system (Zou et al 2008); in case of updating of information in supply chain (Chen et al 2006) and by including the risk preferences of the SC members (He et al 2006).

\subsection{Quantity flexibility contract}

In case of quantity flexibility contract, the buyer is allowed to modify the order within limits agreed to the supplier as demand visibility increases closer to the point of sale. The buyer modifies the order as he gains better idea of actual market demand over time. Tsay \& Lovejoy (1999) proposed quantity flexibility contracts for two independent members of the supply chain model to design incentives for the two parties. The model also discussed the causes of inefficiency in such relationship and suggested remedies. This type of contracts lead all the members motivated to the system wide optimal outcome. The efficiency can be improved when buyer is ready to pay more to the supplier for increased flexibility. Tsay \& Lovejoy (1999) proposed a framework for the design of quantity flexibility in three level supply chains, behavioural models in response to quantity flexibility contracts and the impact on the supply chain performance measures: inventory levels and order variability. More output flexibility comes at the expense of greater inventory cost, so inventory management has been viewed as the management of process flexibilities. It is observed that the quantity flexibility contracts can dampen the transmission of order variability throughout the supply chain. Barbarosoglu (2000) has proposed a decision support model for improving supplier-buyer coordination by using supply contracts. By including the buyer's commitment as a function of time at the contract renewal time, the supply chain nervousness can be reduced. A pricing model is formulated to address partnership expectations for a fair sharing of savings of the supply chain members. Milner \& Rosenblatt (2002) analysed two period quantity flexibility contract in which the buyer is allowed to adjust second order paying a per unit order adjustment penalty. This contract can reduce the potentially negative effect of correlation of demand between two periods, but the order quantity flexibility reduces the profits of the buyer. BarnesSchuster et al (2002) proposed two period options contracts where buyer has flexibility to respond to market changes in second period and coordinate the supply chain channel. Sethi et al (2004) developed a model to analyse a quantity flexibility contract involving multiple periods, rolling horizon demand and forecast updates including demand and price information updates.

There are some other contracts proposed in the literature, which are revenue sharing contracts, contracts based on discounts and profit sharing contracts. In revenue sharing contract, the supplier charges the buyer a low wholesale price and shares a fraction of the revenues generated by the buyer (Giannoccaro \& Pontrandolfo 2004, Cachon \& Larviere 2005 and Koulamas 2006). The SC members can design contracts based on discounts: lot size based or volume based. A discount is lot size based if the pricing schedule offers discounts based on the quantity ordered in a single lot. A discount is volume based if the discount is based on the total quantity purchased over a given period regardless of the number of lots purchased over that period (Rubin \& Benton 2003 and Weng 2004). Chauhan \& Proth (2005) proposed a profit sharing model under price dependent demand proportional to their risks based on expected customer demand. 
Two coordinated contracts (namely buyback and quantity flexibility) are considered in this study to compare the situation of independent working of supply chain members with the situation under coordination by contracts. These two contracts are considered for the present analysis as there is a shift of risk between the supplier and the buyer while proposing these contracts. The other reason is to compare a price based contract with a quantity based contract.

The following gaps in the literature are identified which motivated to propose a model on coordination by contracts.

- The contracts have been discussed in isolation. There seems to be very little work reported in comparing different contracts with a view to study its impact on the overall performance of the supply chain.

- The contracts are applied first in the supply chain followed by determination of optimal order quantity of the supply chain. The reverse approach (i.e. evaluating optimal order quantity of supply chain followed by introducing contracts) may give better results, which is explored in this paper and will justify the comparison between the contracts.

- The performance measure considered in most of the contracts is expected profits. The other performance measures such as average sales, units-short, leftover inventory, revenues realized, salvage realized, goodwill cost incurred, and flexibility provided in the terms of price or quantity can also be explored. Moreover, the analysis of SC contracts may form a basis for the development of future relationship between the supply chain members. It is essential to know the conditions under which it will be beneficial for the members to adopt contracts to develop these relationships.

- The profit functions of the supply chain members may change after implementing contracts. There is a need to explore the introduction of new terms or elimination of old terms from the case of no coordination (independent case) after implementing the contracts. For example, in a single period SC, the supplier has no salvage term in independent case but it may appear when buyback contracts are introduced in SC. Similarly in quantity flexibility contracts, when demand is less than the minimum commitment of buyer, there is no goodwill term in the profit equations of supplier and buyer.

- In the literature, much emphasis is given to two-level supply chain because of simple case. The consideration of more than two level supply chains needs to be explored.

- The elements of coordination like coherency and mutuality can guide the supply chain members to achieve coordination by contracts.

Based on the above observations and gaps, an attempt has been made in this paper to evaluate the impact of contracts on the performance measures of three-level SC under same demand conditions and same cost parameters. The model proposed in this paper has defined the profit functions of various supply chain members as defined by Cachon (2004). The current literature on the supply chain contracts emphasizes more on two-level supply chains with the objective of maximizing profits or minimizing costs (Tsay \& Lovejoy 1999, BarnesSchuster et al 2002, Milner \& Rosenblatt 2002 and Yao et al 2008). The proposed model in this paper extends the SC coordination contracts to three-level supply chain and explores various performance measures, which may have impact on the decision making as well as selection of some contract. The model may also help decision makers to select the beneficial contracts at various interfaces of the supply chain under identical demand conditions and same cost/price parameters. It has also been explored that various elements of coordination like interdependency, coherency and mutuality are pre-requisites to coordination. The existing literature lacks in linking such coordination elements with the supply chain contracts. This 
linkage may help to motivate SC members to initiate coordination contracts, which is the need of an hour in the present competition and globalization of supply chain.

\subsection{Elements of coordination}

The contracts help the supply chain members to achieve coordination by adjusting the order quantity and sharing some risk and profits for the compensation of the adjustment. From the definition of coordination and the characteristics of supply chain contracts, the elements of coordination theory are very much applicable in supply chain contracts, which can be described as:

2.3a Interdependency: Interdependency can be defined as when actions taken by one referent system affect the actions or outcomes of another referent system (McCann \& Ferry 1979). The supply chain members are interdependent on each other for the transfer of money, quantity and information. The supplier (upstream member of supply chain) relies upon buyer (downstream member) because of economies of scale, reputations of downstream members and downstream member's knowledge about local market. Interdependency is inherent in supply chains: members may be interdependent due to mutual information needs, transfer of funds and flow of physical units from one member to other.

2.3b Coherency: Coherency can be defined as the degree of consistency of reasoning across organizational borders through diffusing common understanding (Simatupang et al 2002). The supply chain members are expected to make decisions in coherence with the whole supply chain. The quantity floating in the supply chain must be the optimal order quantity for the whole supply chain.

2.3c Mutuality: The mutuality of coordination can be defined as the underlying values of responsibility among partners with a strong emphasis on sustaining relationship in order to build effective goal attainment. The literature on social contract has recognized that any relationship among business partners must contribute to a climate of mutuality (Campbell 1997). The mutuality norm suggests that each partner contributes to significant value and is entitled to an equitable and fair distribution of outcomes. In a typical supply chain, these outcomes could be: revenues generated, net profits and mutual sharing of risk (overstock/understock). The contract parameters are decided mutually so that the expected profits of all members are more than the case of 'no coordination'. Typically, the contract parameters include: cost and price related information and quantity to be shipped in the SC.

\section{Development of an analytical model}

The supply chain considered in this paper is single-manufacturer-single-distributor-singleretailer adding some value to the product. The demand is assumed to be stochastic with given parameters (mean and standard deviation). After analysing the costs incurred, the supply chain members decide their wholesale prices/price of product. It is assumed that the retailer is interested in estimating the optimal order quantity based on his relevant cost and price data. This decision may not be favourable to other supply chain members and may result in conflict between retailer and other members (distributor and manufacturer). To make the decisions of all supply chain members coherent and considering mutuality, the model proposed here discusses two contracts: buyback and quantity flexibility with corresponding decision variables. This model may act as a decision-making tool for planning and estimating the 
decision variables prior to the realization of actual demand. The following are the members of supply chain considered in the analytical model.

\subsection{Manufacturer}

The manufacturer is the extreme upstream member producing the goods by taking orders from the downstream member, distributor. In the single period problem, the manufacturer is expected to deliver all the units demanded from downstream member (assumed infinite capacity). The manufacturer incurs marginal cost (production cost) and gets wholesale price for each unit of product sold to the distributor. The manufacturer's profits are dependent on the units sold. More the units sold by manufacturer, more profits the manufacturer will get. The manufacturer incurs goodwill cost for the demand, which cannot be met by manufacturer. There is no salvage value for manufacturer in single period model, but when contracts are adopted, the manufacturer gets salvage value for unsold units at the end of period.

\subsection{Distributor}

The distributor is an intermediate member of supply chain, who fulfills the demand of retailer and in turn places orders to the manufacturer. The distributor incurs marginal cost for acquiring each unit and goodwill cost for unmet demand. There is no salvage value at the distributor's end, as the distributor is assumed to fulfill all demand ordered by the retailer. Since the wholesale price for each unit increases the profits of distributor, the distributor will also be interested to sell large quantity to downstream member i.e. retailer.

\subsection{Retailer}

The retailer is the extreme downstream member of the supply chain who orders his optimal order quantity (using newsboy model) to the upstream member both in case I 'no coordination' (explained in later section) of three-level supply chain. The optimal order quantity of the whole supply chain (SCQ) is larger than the retailer's optimal order quantity. The retailer has to pay large wholesale price for each unit to the distributor when SCQ is ordered, which reduces the profit function of the retailer. The performance measures at the retailer, which increase the profit function of the retailer are revenues generated from the sale of units and salvage value for unsold units at the end of period. The other cost incurred by the retailer are marginal cost for acquiring each unit and goodwill cost for unmet demand.

The consideration of expectations of more than one member (all three supply chain members) of the supply chain simultaneously needs modification and extension of newsboy model. The proposed model will help in designing contracts to satisfy the expectations of the SC members and to coordinate the supply chain with respect to the base case of 'no coordination'. The model proposed here may help in visualizing the complexity in coordinating the supply chain with three numbers of levels.

\subsection{Notations and Assumptions}

The notations and assumptions of the model are described below:

\section{Notations}

\section{Index}

m: Manufacturer,

d: Distributor,

r: Retailer 
Manufacturer
$c_{m}:$ Production cost
$g_{m}:$ Goodwill cost
$s_{m}:$ Salvage
$w_{m d}:$ Wholesale price charged by
$\quad$ manufacturer to distributor
$q_{r}: \quad$ Optimal quantity of retailer

$S(q)$ : Expected sales at the end of period which can be defined as:
Distributor

$c_{d}$ : Marginal cost

$g_{d}$ : Goodwill cost

$s_{d}$ : Salvage

$w_{d r}$ : Wholesale price charged by distributor to retailer

$Q_{s c}^{*}$ : Optimal order quantity of supply chain
Retailer

$c_{r}$ : Marginal cost

$g_{r}:$ Goodwill cost

$s_{r}$ : Salvage

$p$ : Price of product

$$
\begin{aligned}
& S(q)=q(1-F(q))-\int_{0}^{q} y f(y) d y \\
& S(q)=q-\int_{0}^{q} F(y) d y .
\end{aligned}
$$

The buyers are subjected to random demand ' $d m$ ' with $F$ distribution function and $f$ is the density function. $F$ is differentiable and strictly increasing (with $F(0)=0$ ). Also,

$$
\bar{F}(x)=1-F(x) \text { and } D=E[d m] .
$$

Decision variables for buyback contract include

$\beta_{1} \quad$ : Buyback price at which retailer returns the unsold units to the distributor at the end of period

$\beta_{2}$ : Buyback price at which distributor returns the unsold units to the manufacturer at the end of period

Decision variables for quantity flexibility contract include

$(1-\delta) Q_{s c}^{*} \quad: \quad$ Minimum purchase quantity committed by retailer, Where $0<\delta<1$

$Q_{s c}^{*} \quad:$ Maximum order quantity committed by distributor (with the consent of manufacturer)

$\delta \quad: \quad$ Fraction of the quantity flexibility provided to the retailer

Expected Performance measures (Monetary units (MU))

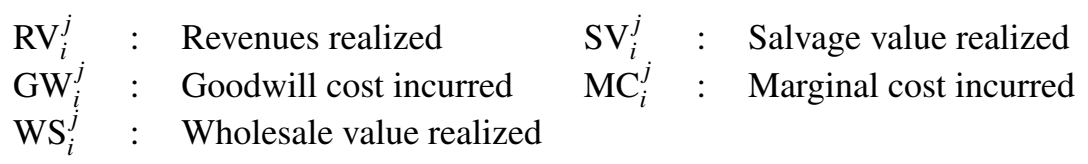

Expected Performance measures: (Number of units at the end of period)

$\mathrm{AS}_{i}^{j}:$ Average sales $\mathrm{LU}_{i}^{j}:$ Leftover units $\mathrm{US}_{i}^{j}:$ Units short

Where $i=\{\mathrm{r}$ : retailer, d: distributor, m: manufacturer $\}$ and $j=\left\{{ }^{\prime} *^{\prime}\right.$ : optimal case, B: buyback contract, QF: quantity flexibility contract $\}$ 
Performance measures in (MU)

$$
\begin{array}{lrrr}
\mathrm{RV}_{i}=p S(q) \quad \mathrm{SV}_{i}= & s_{i}(q-S(q)), & \mathrm{GW}_{i}=g_{i}(d m-q), \\
& & \text { if }(d m<q, \text { otherwise } 0) & \text { if }(d m>q, \text { otherwise } 0) \\
\mathrm{MC}_{i}=c_{i} q & \mathrm{WS}_{i}=w_{i, i+1}(q) & \\
\text { (MU: Monetary Units). } &
\end{array}
$$

Assumptions

- A single period model with short life cycle product is assumed.

- The demand is assumed to be normally distributed with $\sim \mathrm{N}\left(\mu, \sigma^{2}\right)$.

- There is an infinite capacity at the manufacturer's end.

- It is assumed that $\mathrm{p}$ (price of product) $>w_{d r}$ (wholesale price charged by distributor to retailer) $>w_{m d}$ (wholesale price charged by manufacturer to distributor) $>c_{m}$ (cost of manufacturer) must follow.

- The salvage value of manufacturer is present only when the downstream member returns unsold inventory.

- In case of leftover inventory at the end of period, the retailer in buyback contract can return full-unsold inventory back to the distributor $\left(\beta_{1}>s_{r}\right)$. The distributor also returns the unsold inventory to the manufacturer $\left(\beta_{2}>s_{d}\right)$.

- The maximum commitment by the manufacturer is assumed to be the optimal order quantity of supply chain in quantity flexibility contract.

To realize the importance of coordination by contracts and to implement the elements of coordination in the whole supply chain, two cases have been explored. The first case, Case I is of 'No coordination case' in which the supply chain members act independently and there is no coordination between them. The retailer decides optimal order quantity based on his local cost and price parameters. The various performance measures are evaluated in the independent case for all the members. The 'No coordination case' is compared with the Case II, 'coordination case', which can be implemented in two steps. The first step covers the 'coherency' element of coordination based on determining the optimal order quantity of the supply chain. The first step may not be favourable to all the supply chain members; hence, in the second step the other element of coordination 'mutuality' is explored with the help of supply chain contracts. The profit functions of retailer, distributor and manufacturer can be defined as:

$$
\begin{aligned}
P_{r} & =f\left(R V_{r}, S V_{r}, G W_{r}, W_{d r}, M C_{r}\right) \\
P_{d} & =f\left(S V_{d}, G W_{d}, W_{d r}, W_{m d}, M C_{d}\right) \\
P_{m} & =f\left(S V_{m}, G W_{m}, W_{m d}, M C_{m}\right) .
\end{aligned}
$$

The mutual decision-making regarding the decision variables of contracts may help all the members to achieve more profits than the profits of Case I. The schematic diagram for the proposed model is presented in figure 1. The two cases are described below for three level supply chain.

\subsection{Proposed model}

An analytical model for three-level supply chain is presented by defining the profit functions for retailer, distributor and manufacturer. Also, the changes in various performance measures in two cases Case I: 'No coordination case' (Independent case) and Case II: 'Coordination case' are described below from equations/inequalities (1) to (25). 


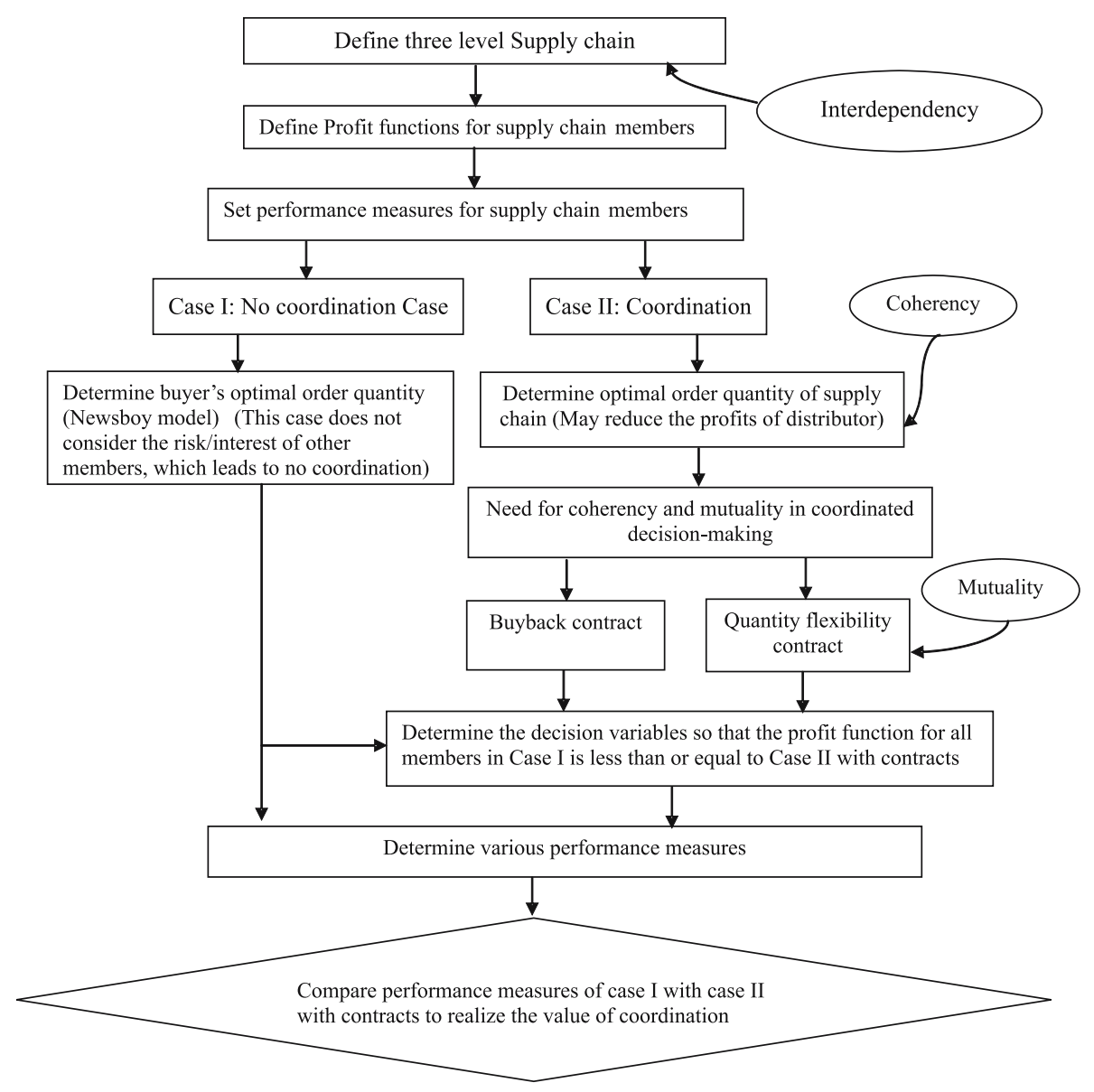

Figure 1. A schematic diagram of proposed model on supply chain coordination by contracts.

3.5a Case I: No coordination case: The profit function $\left(P_{r}(q)\right)$ of the retailer in case of no coordination (with retailer's optimal order quantity) is dependent on the following: (Revenue, Salvage, Goodwill cost incurred, Wholesale value and Marginal cost incurred):

Profit function $\left(P_{r}(q)\right)=$ Revenues realized + salvage realized - goodwill cost incurred wholesale value realized - marginal cost incurred, which can be defined as in equation (1)

$$
P_{r}(q)=p S(q)+s_{r}(q-S(q))-g_{r}(D-q)-w_{d r} q-c_{r} q
$$

The profit function of the distributor in case of no coordination is dependent on the following performance measures (Goodwill cost incurred, wholesale value realized and marginal cost incurred):

Profit function $P_{d}(q)=-$ Goodwill cost incurred + wholesale value realized - marginal cost incurred, which can be defined as:

$$
P_{d}(q)=-g_{d}(D-q)+w_{d r} q-c_{d} q-w_{m d} q
$$

The profit function $P_{m}(q)$ of the manufacturer is dependent on the following performance measures: 
Profit function $P_{m}(q)=-$ Goodwill cost incurred + wholesale value realized - marginal cost incurred, which can be defined as:

$$
P_{m}(q)=-g_{m}(D-q)+w_{m d} q-c_{m} q
$$

The optimal order quantity of the retailer can be determined as per Newsboy model by differentiating equation (1) with respect to order quantity as:

$$
F\left(q_{r}\right)=1-\left(\frac{c_{r}+w_{d r}-s_{r}}{p-s_{r}+g_{r}}\right)
$$

3.5b Case II: Coordination case: The optimal order quantity of the whole supply chain

$$
F\left(Q_{s c}^{*}\right)=1-\frac{c_{m}+c_{d}+c_{r}-s_{r}}{p-s_{r}+g_{m}+g_{d}+g_{r}} .
$$

The profit function $P_{r}\left(Q_{s c}^{*}\right)$ of the retailer are dependent on the same performance measures as that of case I but evaluated with $Q_{s c}^{*}$ instead of $q_{r}$ can be defined as:

$$
P_{r}\left(Q_{s c}^{*}\right)=p S\left(Q_{s c}^{*}\right)+s_{r}\left(Q_{s c}^{*}-S\left(Q_{s c}^{*}\right)\right)-g_{r}\left(D-Q_{s c}^{*}\right)-w_{d r} Q_{s c}^{*}-c_{r} Q_{s c}^{*} .
$$

The profit function $P_{d}\left(Q_{s c}^{*}\right)$ of the distributor is dependent on the same performance measures as that of case I but evaluated with $Q_{s c}^{*}$ instead of $q_{r}$ with addition of new measure: wholesale value charged by the manufacturer

$$
P_{d}\left(Q_{s c}^{*}\right)=-g_{d}\left(D-Q_{s c}^{*}\right)+w_{d r} Q_{s c}^{*}-c_{d} Q_{s c}^{*}-w_{m d} Q_{s c}^{*} .
$$

The profit function of the manufacturer when $Q_{s c}^{*}$ is produced (the same performance measures as in equation (3) but with $Q_{s c}^{*}$ order quantity)

$$
P_{m}\left(Q_{s c}^{*}\right)=-g_{m}\left(D-Q_{s c}^{*}\right)+w_{m d} Q_{s c}^{*}-c_{m} Q_{s c}^{*} .
$$

The profit function of the distributor in case of buyback contracts is dependent on the following performance measures:

Profit function $P_{d}^{B}\left(Q_{s c}^{*}\right)=$ Revenues realized + buyback value realized - goodwill cost incurred - wholesale value realized - marginal cost incurred, which can be defined as:

$$
P_{r}^{B}\left(Q_{s c}^{*}\right)=p S\left(Q_{s c}^{*}\right)+\beta_{1}\left(Q_{s c}^{*}-S\left(Q_{s c}^{*}\right)\right)-g_{r}\left(D-Q_{s c}^{*}\right)-w_{d r} Q_{s c}^{*}-c_{r} Q_{s c}^{*} .
$$

The profit function of the distributor in case of buyback contracts is dependent on the following performance measures:

Profit function $P_{d}^{B}\left(Q_{s c}^{*}\right)=-$ goodwill cost incurred + wholesale value realized - marginal cost incurred - Buyback value incurred + salvage realized, with additional measure: the buyback value realized by manufacturer for unsold units defined as:

$$
\begin{aligned}
P_{d}^{B}\left(Q_{s c}^{*}\right)= & -g_{d}\left(D-Q_{s c}^{*}\right)+w_{d r} Q_{s c}^{*}-c_{d} Q_{s c}^{*}-w_{m d} Q_{s c}^{*} \\
& -\beta_{1}\left(Q_{s c}^{*}-S\left(Q_{s c}^{*}\right)\right)+\beta_{2}\left(Q_{s c}^{*}-S\left(Q_{s c}^{*}\right)\right) .
\end{aligned}
$$

The profit function $P_{m}^{B}\left(Q_{s c}^{*}\right)$ of the manufacturer in case of buyback contracts is dependent on the following performance measures: 
Profit function $\left(P_{m}^{B}\left(Q_{s c}^{*}\right)\right)=-$ Goodwill cost incurred + wholesale value realized marginal cost incurred - buyback value incurred + salvage realized, which can be defined as:

$$
\begin{aligned}
P_{m}^{B}\left(Q_{s c}^{*}\right)= & -g_{m}\left(D-Q_{s c}^{*}\right)+w_{m d} Q_{s c}^{*}-c_{m} Q_{s c}^{*} \\
& -\beta_{2}\left(Q_{s c}^{*}-S\left(Q_{s c}^{*}\right)\right)+s_{m}\left(Q_{s c}^{*}-S\left(Q_{s c}^{*}\right)\right)
\end{aligned}
$$

By setting following inequalities, the parameters $\beta_{1}$ and $\beta_{2}$ can be determined

$$
\begin{aligned}
& P_{r}^{B}\left(Q_{s c}^{*}\right) \geq P_{r}(q), P_{d}^{B}\left(Q_{s c}^{*}\right) \geq P_{d}(q), P_{m}^{B}\left(Q_{s c}^{*}\right) \geq P_{m}(q) \\
& \left(p-s_{r}\right) S(q)+\left(s_{r}+g_{r}-w_{d r}-c_{r}\right) q \\
& \beta_{1} \geq \frac{+\left(w_{d r}+c_{r}-g_{r}\right) Q_{s c}^{*}-p S\left(Q_{s c}^{*}\right)}{Q_{s c}^{*}-S\left(Q_{s c}^{*}\right)} \\
& \beta_{2}-\beta_{1} \geq \frac{\left(g_{d}+w_{d r}-c_{d}-w_{m d}\right) q+\left(c_{d}+w_{m d}-g_{d}-w_{d r}\right) Q_{s c}^{*}}{Q_{s c}^{*}-S\left(Q_{s c}^{*}\right)} \\
& \beta_{2} \leq \frac{\left(g_{m}+w_{m d}-c_{m}+s_{m}\right) Q_{s c}^{*}-s_{m} S\left(Q_{s c}^{*}\right)+q\left(c_{m}-g_{m}-w_{m d}\right)}{Q_{s c}^{*}-S\left(Q_{s c}^{*}\right)} .
\end{aligned}
$$

The profit function $P_{d}^{Q F}\left(Q_{s c}^{*}\right)$ of the retailer in case of quantity flexibility contracts is dependent on the following performance measures:

Profit function $P_{d}^{Q F}\left(Q_{s c}^{*}\right)=$ Revenues realized + salvage realized (when demand is less than minimum commitment (a)) + Buyback value realized (when demand is between minimum and maximum commitment (b)) - goodwill cost incurred (when demand is more than maximum commitment (c)) - wholesale value realized - marginal cost incurred

(a) When demand $d m<=(1-\delta) Q_{s c}^{*}$

$$
\begin{aligned}
P_{r}^{Q F}\left(Q_{s c}^{*}\right)= & p S\left((1-\delta) Q_{s c}^{*}\right)+s_{r}\left((1-\delta) Q_{s c}^{*}-d m\right) \\
& -w_{d r}(1-\delta) Q_{s c}^{*}-c_{r}(1-\delta) Q_{s c}^{*} .
\end{aligned}
$$

(b) When $(1-\delta) Q_{s c}^{*}<d m<=Q_{s c}^{*}$

$$
P_{r}^{Q F}\left(Q_{s c}^{*}\right)=p S\left(Q_{s c}^{*}\right)+w_{d r}\left(Q_{s c}^{*}-d m\right)-w_{d r} Q_{s c}^{*}-c_{r} Q_{s c}^{*}
$$

(c) When $d m>Q_{s c}^{*}$

$$
P_{r}^{Q F}\left(Q_{s c}^{*}\right)=p S\left(Q_{s c}^{*}\right)-w_{d r} Q_{s c}^{*}-c_{r} Q_{s c}^{*}-g_{r}\left(d m-Q_{s c}^{*}\right) .
$$

The profit function $P_{a}^{Q F}\left(Q_{s c}^{*}\right)$ of the distributor in case of quantity flexibility contracts is dependent on the following performance measures:

Profit function $P_{a}^{Q F}\left(Q_{s c}^{*}\right)=$ Wholesale value realized - marginal cost incurred - buyback value incurred (for unsold units when demand is between minimum and maximum commitment) - goodwill cost realized (when demand is more than maximum commitment)

(a) When demand $d m<=(1-\delta) Q_{s c}^{*}$

$$
P_{d}^{Q F}\left(Q_{s c}^{*}\right)=w_{d r}(1-\delta) Q_{s c}^{*}-c_{d}(1-\delta) Q_{s c}^{*}-w_{m d}(1-\delta) Q_{s c}^{*}
$$


(b) When $(1-\delta) Q_{s c}^{*}<d m<=Q_{s c}^{*}$

$$
\begin{aligned}
P_{d}^{Q F}\left(Q_{s c}^{*}\right)= & w_{d r} Q_{s c}^{*}-c_{d} Q_{s c}^{*}-w_{m d} Q_{s c}^{*} \\
& -w_{d r}\left(Q_{s c}^{*}-d m\right)+w_{m d}\left(Q_{s c}^{*}-d m\right)
\end{aligned}
$$

(c) When $d m>Q_{s c}^{*}$

$$
P_{d}^{Q F}\left(Q_{s c}^{*}\right)=w_{d r} Q_{s c}^{*}-c_{d} Q_{s c}^{*}-w_{m d} Q_{s c}^{*}-g_{d}\left(d m-Q_{s c}^{*}\right)
$$

The profit function of the manufacturer in case of quantity flexibility contracts is dependent on the following performance measures:

Profit function $P_{m}^{Q F}\left(Q_{s c}^{*}\right)=-$ goodwill cost incurred (when demand is more than maximum commitment (a)) + wholesale price charged to distributor - marginal cost incurred - buyback value incurred (demand is between minimum and maximum commitment (b)) + salvage value (demand is between minimum and maximum commitment (c)), which can be defined as:

(a) When demand $d m<=(1-\delta) Q_{s c}^{*}$

$$
P_{m}^{Q F}\left(Q_{s c}^{*}\right)=w_{d r}(1-\delta) Q_{s c}^{*}-c_{m}(1-\delta) Q_{s c}^{*}-w_{m d}(1-\delta) Q_{s c}^{*}
$$

(b) When $(1-\delta) Q_{s c}^{*}<d m<=Q_{s c}^{*}$

$$
P_{m}^{Q F}\left(Q_{s c}^{*}\right)=w_{m d} Q_{s c}^{*}-c_{m} Q_{s c}^{*}-w_{m d}\left(Q_{s c}^{*}-d m\right)+s_{m}\left(Q_{s c}^{*}-d m\right)
$$

(c) When $d m>Q_{s c}^{*}$

$$
P_{m}^{Q F}\left(Q_{s c}^{*}\right)=w_{m d} Q_{s c}^{*}-c_{m} Q_{s c}^{*}-g_{m}\left(d m-Q_{s c}^{*}\right)
$$

From inequalities (12)

$$
\text { The fraction of quantity flexibility }(1-\delta) \geq \frac{q}{Q_{s c}^{*}} \text {. }
$$

\subsection{Comparison of 'no coordination' with coordination}

In Case I, the retailer determines the optimal order quantity based on his cost and price data as shown in equation (3). The profit function of the manufacturer/distributor is directly proportional to order quantity and among the cost and price data of the manufacturer/distributor, the wholesale price per unit is greater. The upstream member will try to push large quantity to the downstream member to reduce overstock cost, whereas the downstream member will order his optimal order quantity to reduce the overstock cost. This difference in decisions for order quantity causes conflict among the supply chain members. There is a scope to increase the order quantity than the optimal order quantity of the retailer to improve the profits of manufacturer and distributor also. The case I may not be acceptable to the manufacturer and the distributor. Also, the decision regarding order quantity is not coherent to the whole supply chain.

As per the coherency element of coordination, the supply chain members need to determine the optimal order quantity of the supply chain jointly. The members may consider the cost and 
price data of all the members while determining the order quantity to consider the risks of all the members. The supply chain optimal order quantities for (SCQ) three-level supply chain can be determined by using equation (5). The SCQ is more than the optimal order quantity of the retailer in case I.

It can be observed from equation (5), the expected profits of the retailer are decreasing because with the increase in order quantity, the retailer may face more overstock and may have to charge high wholesale price and marginal cost. The reductions in expected profits than the Case I may discourage the retailer to agree for SCQ or may leave the SC. As per equation (5), the expected profits may further decrease for the retailer as more and more levels of SC are introduced.

To make the decision coordinated with coherency intact in the SC, supply chain contracts (Buyback contract and quantity flexibility contract) are proposed. The profit functions for two contracts are analysed for three-level SC. The decision variables $\left(\beta_{1}, \beta_{2}, \delta\right)$ are evaluated by considering mutuality in decision-making process. Setting inequalities (12), (13), (14), (15) and (25) can benefit mutual decision-making among supply chain members. These inequalities help in evaluating decision variables and ensuring mutuality by improving the expected profits than the expected profits in case I.

\subsection{Performance measures}

The profit function of all the members is dependent on a number of performance measures defined in assumptions and notations. These performance measures for two cases and for two contracts behave differently or have different impact on the profit functions. There can be an improvement in some of the performance measures and at the same time some performance measures may show decreasing behaviour as the contracts are introduced. But, the changes in the performance measures from the case I may help in realizing the value of coordination in terms of varying performance measures and expected profits of all supply chain members.

Case I-'No coordination case': The various performance measures can be determined when the supply chain members act independently, i.e. when the retailer orders his/her optimal order quantity. These performance measures are set as base to compare this case with other case of coordination comprised of two contracts.

Case II- 'Coordination case': The case II is divided into three sub cases: Optimal case, optimal case with buyback contract and optimal case with quantity flexibility contract, which are discussed below:

3.7a Optimal case: The increase in $Q_{s c}^{*}$ from the optimal order quantity (case I) of the retailer may change the performance measures of all the members of supply chain. The changes in the performance measures and their impact on the profit function of all the members can be observed in table 1. The increase in order quantity leads to reduction in expected profits of the retailer. But, in the optimal case the expected profits of the distributor and the manufacturer are more than the respective expected profits in case I.

The changes in revenues realized, salvage realized and goodwill cost incurred are dependent on expected sales at the end of period. But the wholesale value realized and marginal costs incurred are directly proportional to the order quantity. So, the increase in these performance measures, will lead to reduction in the retailer's expected profits, hence may not be acceptable to the retailer. Even though, this case helps in achieving coherency, but one of the members of supply chain i.e. retailer may not be interested to be part of this SC. A mutual 
Table 1. Impact of optimal case on performance measures with respect to case I.

\begin{tabular}{|c|c|c|c|c|c|c|}
\hline \multirow[b]{2}{*}{$\begin{array}{l}\text { Supply chain } \\
\text { member }\end{array}$} & \multicolumn{6}{|c|}{ Performance measures } \\
\hline & $\begin{array}{l}\text { Revenues } \\
\text { realized } \\
\text { (RV) }\end{array}$ & $\begin{array}{l}\text { Salvage } \\
\text { realized } \\
(\mathrm{SV})\end{array}$ & $\begin{array}{l}\text { Goodwill } \\
\text { incurred } \\
(\mathrm{GW})\end{array}$ & $\begin{array}{l}\text { Wholesale } \\
\text { value realized/ } \\
\text { incurred } \\
\text { (W) }\end{array}$ & $\begin{array}{l}\text { Marginal } \\
\text { cost } \\
\text { incurred } \\
\text { incurred } \\
\text { (MC) }\end{array}$ & Remarks \\
\hline Retailer & Increases & Increases & Decreases & Increases & Increases & Increasing order \\
\hline Profit function & Improves & Improves & Improves & Reduces & Reduces & $\begin{array}{l}\text { quantity reduces } \\
\text { profit function } \\
(W+M C>= \\
R V+S V+G W)\end{array}$ \\
\hline Distributor & - & - & Decreases & Increases & Increases & $\begin{array}{l}\text { Increasing order } \\
\text { quantity improves }\end{array}$ \\
\hline Profit function & - & - & Improves & Improves & Reduces & $\begin{array}{l}\text { profit function } \\
(G W+W>= \\
M C)\end{array}$ \\
\hline Manufacturer & - & - & Decreases & Increases & Increases & $\begin{array}{l}\text { Increasing order } \\
\text { quantity improves }\end{array}$ \\
\hline Profit function & - & - & Improves & Improves & Reduces & $\begin{array}{l}\text { profit function } \\
(G W+W>= \\
M C)\end{array}$ \\
\hline
\end{tabular}

decision-making is required so that the interest of all the SC members should be considered along with coherency in the supply chain. The coordination mechanisms: buyback and quantity flexibility contract may help to incorporate the interests of the retailer also.

3.7b Optimal case with buyback contracts: The distributor acts as a buyer to the manufacturer as well as supplier to the retailer. All members add value to the product throughout the SC. In case of buyback contracts it is required to determine the feasible values of decision variables at two interfaces: Manufacturer-distributor and Distributor-retailer. By applying the coordination element 'mutuality' the inequalities (12) are formulated. The other inequalities (13), (14) and (15) helps in finding feasible values of $\beta_{1}$ and $\beta_{2}$ under the assumptions $\left(s_{r}<\beta_{1}<w_{d r}<p\right)$ and $\left(s_{d}<\beta_{2}<w_{m d}<w_{d r}\right)$. These inequalities also help in determining the lower and upper limits for $\beta_{1}$ and $\beta_{2}$. Various iterations required to simultaneously satisfying these inequalities might increase complexity. The value of expected sales is required to find the values of buyback prices. The expected sales can be determined with the help of simulation, and then a sensitivity analysis can be carried out to find the values of $\beta_{1}$ and $\beta_{2}$ in the best interest of all the supply chain members. There can be more than one value for each $\beta_{1}$ and $\beta_{2}$, in which case a joint mechanism may be adopted to select best value of $\beta_{1}$ and $\beta_{2}$, which improves the profits of the whole supply chain.

It can be observed from table 2 , that the performance measures which changes in the case 'optimal with buyback contracts' is the new term buyback value realized which is determined as $\left(\beta_{1}\left(Q_{s c}^{*}-S\left(Q_{s c}^{*}\right)\right)\right)$ for the retailer. The buyback value is responsible to compensate the losses of the retailer, which the retailer would have faced by ordering $Q_{s c}^{*}$ without contracts. The performance measures introduced in the profit function of the distributor by designing buyback contract are: buyback value incurred, which reduces the profit function. The buyback 


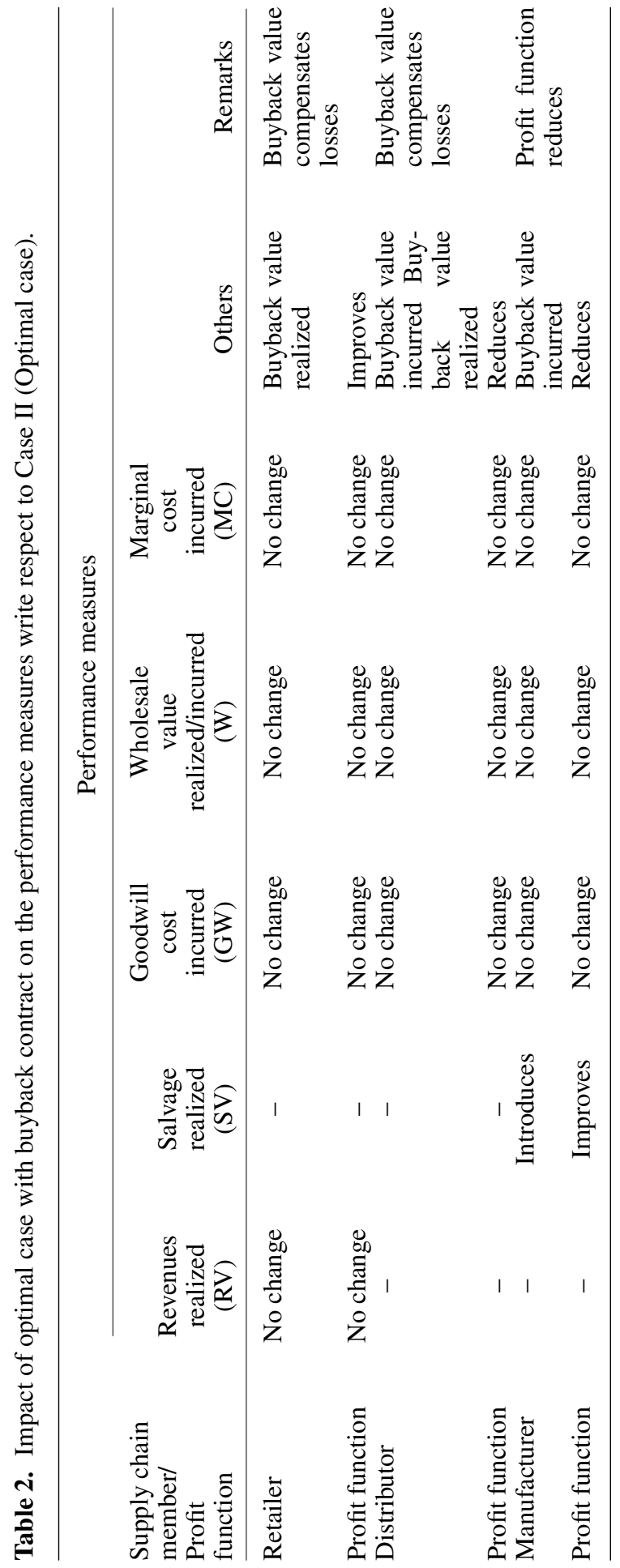


value realized from the manufacturer will improve the profit function. The inequality (12) is defined so as to improve the profit function of members over the case I, the buyback contract ensures coordination with applicability of all three elements of coordination.

The adoption of buyback contract leads to the introduction of new performance measure in the profit function of the manufacturer i.e. salvages value realized (for unsold units at the end of period). The distributor gains buyback value realized by manufacturer. In threelevel SC there is no salvage realized by the distributor. The return of units unsold at the end of period to manufacturer through distributor at buyback price reduces the profit functions of the distributor and the manufacturer from profit functions of the optimal case (of respective levels). The inequalities (12) ensure improvement in the expected profits of the distributor and the manufacturer in case II with buyback contracts over the expected profits of case I.

3.7c Optimal case with quantity flexibility contracts: In the quantity flexibility contract the SC members mutually decide the amount of flexibility in order quantity i.e. fraction of $Q_{s c}^{*}\left(\delta Q_{s c}^{*}\right)$, provided to the retailer. The retailer is expected to commit a minimum order quantity $(1-\delta) Q_{s c}^{*}$ to the distributor as well as to the manufacturer. In turn, the manufacturer commits maximum order quantity, which is considered to be $Q_{s c}^{*}$ in the present model. The retailer is the extreme downstream member having more knowledge about customer demand. The retailer may change the order quantity immediately before the selling season as he gets expected advance information on demand. The benefit of offering such contracts is that when demand is less than minimum commitment, the wholesale price and marginal cost is charged for only $(1-\delta) Q_{s c}^{*}$ units (table 3 ). In addition, when the demand lies between minimum commitment and maximum commitment, the unsold units are bought back by the distributor/manufacturer at the wholesale price.

The decision variable of quantity flexibility contract can be determined by using inequality (25). There can be three cases in this contract depending on the demand. In case the demand is less than minimum commitment, the retailer is charged less wholesale price and incur less marginal cost. The unsold units are salvaged at the end. If the demand is lying between minimum commitment and maximum commitment, the distributor buys back the unsold units at wholesale price $w_{d r}$ from retailer. Hence, the contract improves the profit function of the retailer as well as other performance measures like wholesale value realized, marginal cost incurred and buyback value realized.

The distributor behaves like retailer for the manufacturer in three level supply chains. The model is proposed for single period, hence the leftover units, units short and average sales are same in all cases of coordination. The manufacturer will bet salvage value realized. The expected profits of the retailer may be more because of the reduction in wholesale realized and marginal cost incurred. The profit function of distributor may improve because of the introduction of buyback value realized for unsold units.

\subsection{Realization of coordination elements by supply chain contracts}

The upstream (manufacturer/distributor) SC member requires order information as well as order payments from the downstream member (distributor/retailer). The downstream members in turn require order quantity to satisfy end customer. In this way the SC members are interdependent (in built interdependency in supply chain) on each other whether they are willing to coordinate with each other or not. But, for the effective management of interdependencies, the coordination elements may play very important role and also help in achieving supply chain coordination. 


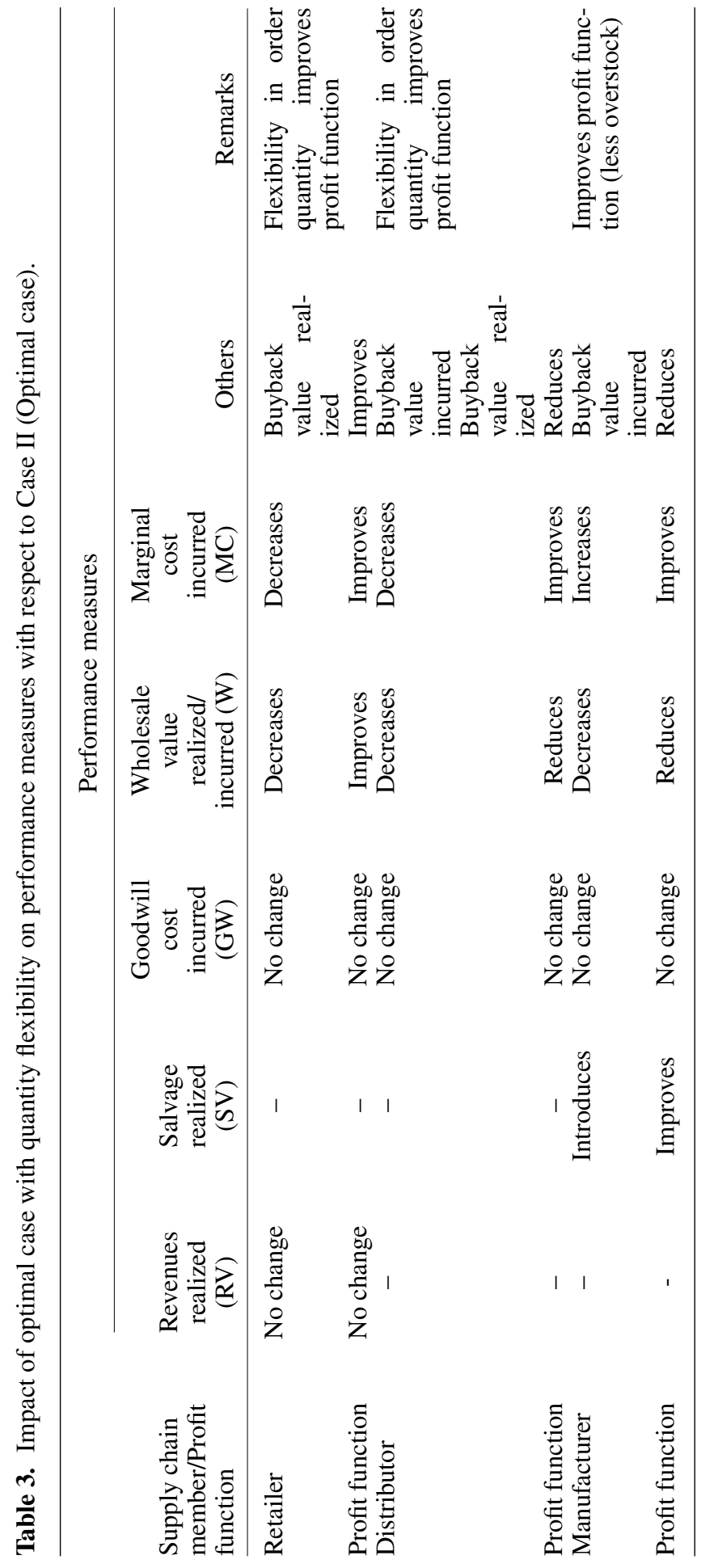


The elements of coordination are implemented so that the interdependency between the SC members becomes stronger. The SC members become more interdependent with the adoption of coordination mechanisms. To implement coordination mechanism the members depend on each other for joint planning of mechanisms, effective implementation of mechanisms, joint determination of decision variables of coordination mechanisms and risk/reward sharing after implementing coordination mechanisms. For example, the coordination mechanism, SC contract, which has been discussed in this paper, may lead to more interdependency between the SC members in following terms:

- Joint selection of type of contract (Buyback or Quantity flexibility)

- Sharing of cost and price information among each other

- Joint determination of decision variables (buyback price, fraction of quantity flexibility)

- Joint evaluation of performance measures.

The SC members may become more interdependent with the introduction of more levels in the supply chain. The risk of supply due to uncertainty of demand may increase with the increase in the number of SC members. This may be due to difficulty to gather information from extreme member and due to the information distortion within each level. The information distortion may also increase risks of overstock or under stock in the supply chain.

A well-coordinated SC can be one where the gap between supply and demand is least. In the absence of demand information, the general tendency is that each member will determine his optimal order quantity, which may not be acceptable to other members and to overall SC. Mostly, the extreme downstream member has maximum knowledge about end customer demand, so he dominates in deciding about order quantity. There is a need for coherent decision-making throughout the SC with single order quantity. Also, each member is entitled to get the rewards as per the value addition. So, the cost and risk every member puts in SC needs to be taken care.

There can be cases where there is no coherency but still mutuality element of coordination can be achieved. Such a case may arise when the members share rewards at the end of period, regardless whether the order quantity is coherent or not. The situation can prevail in quantity flexibility contracts, where the achievement of expected profits can be set as starting point and then determine the minimum and maximum commitment. But, buyback contract may not give any value in case coherency is absent. The independent decision-making is done by newsboy model in which the overstock and understock trade-off is already handled, so there is no need of buyback contracts.

The coherency in order quantity can be absent when the number of levels in SC is increased. It is difficult to handle huge data on the cost of all members to find SQC. The interdependent members can devise some mechanisms to mutually share rewards at the end of period. It can also be interpreted as, the member who takes independent decision regarding ordering quantity (dominant party), has to share his rewards with other members of the supply chain.

The mutuality element in conjunction with mutual determination of decision variables of contracts helps in compensating the members if the members face losses because of ordering coherent order quantity. The role of SC contracts is justified in conjunction with following mutuality by the supply chain members. The absence of mutuality may also lead to dominance of one of the member in the SC. In the absence of mutuality, there can be a biased decision on the determination of performance measures and decision variables.

In the absence of mutuality, the decision variables are evaluated so that coherent order quantity can be achieved. This may lead some members to change their cost and price data. Different experiments/iterations can be carried out to set decision variables. 


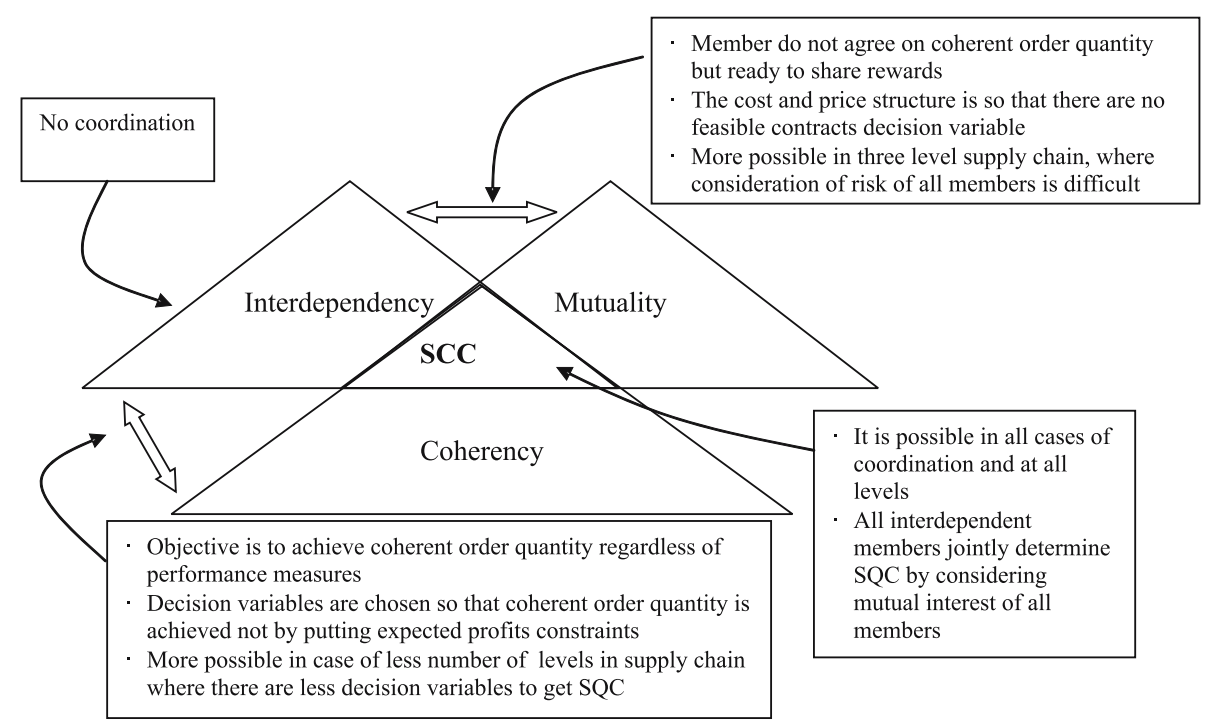

Figure 2. Relationship between various coordination elements.

The coordination elements are related to each other as shown in figure 2 . The performance of SC members may be reduced when either coherency is absent or mutuality is absent. It may lead to dominance in the SC, which may not be desirable for a coordinated supply chain.

Similarly, for satisfying constraint C. 1 for quantity flexibility contracts, the decision variable that is flexibility in order quantity $\delta$ follows C.5. Again $\delta$ is dependent on $q$ and $Q_{s c}^{*}$, which are random components.

The model proposed in this paper gives an idea about the impact of contracts on various performance measures. The challenge still lies in determining the decision variables of SC contracts in the proposed model and the models presented in literature so far is. It can be observed that to achieve the objective of maximizing the expected profits, the feasible values of decision variables are required to be determined. The problem can be formulated as presented in figure 3.

The problem formulation in three-level supply chain presents following insights:

(i) The objective function of the formulation maximizes the expected profits of whole coordinated supply chain. Supply chain members can coordinate when they all agree to order $Q_{s c}^{*}$ throughout supply chain.

(ii) The constraint C.1 signifies that SC members ( $i=r, d$ and $m$ ) expect the improvement in their respective profits while coordinating with each other using contracts $(j=B, Q F)$.

(iii) It can be observed from constraints (C.2 to C.4), which are resulted to satisfy C.1, that major difficulty is in determining the upper bound for $\beta_{1}$ and the lower bound for $\beta_{2}$. The other complexity is the presence of random demand component in these constraints.

A method needs to be devised to determine $\beta_{1}, \beta_{2}$ and $\delta$ so that all the constraints are satisfied and improves the objective function. One of the methods is simulation. Simulating the present scenario with assumed distribution can help in determining the expected sales both in Case I and Case II. The average of expected sales can be substituted in the inequalities to estimate the bounds on the decision variables. The major consideration while estimating the 
Maximize the objective function (Profit)

$$
\operatorname{Max}_{i}^{j}\left(Q_{s c}^{*}\right)
$$

Subject to the following constraints:

$$
\begin{gathered}
P_{i}^{j}\left(Q_{s c}^{*}\right) \geq P_{i}(q) \\
\beta_{1} \geq \frac{\left(p-s_{r}\right) S(q)+\left(s_{r}+g_{r}-w_{d r}-c_{r}\right) q+\left(w_{d r}+c_{r}-g_{r}\right) Q_{s c}^{*}-p S\left(Q_{s c}^{*}\right)}{Q_{s c}^{*}-S\left(Q_{s c}^{*}\right)} \\
\beta_{2}-\beta_{1} \geq \frac{\left(g_{d}+w_{d r}-c_{d}-w_{m d}\right) q+\left(c_{d}+w_{m d}-g_{d}-w_{d r}\right) Q_{s c}^{*}}{Q_{s c}^{*}-S\left(Q_{s c}^{*}\right)} \\
\beta_{2} \leq \frac{\left(g_{m}+w_{m d}-c_{m}+s_{m}\right) Q_{s c}^{*}-s_{m} S\left(Q_{s c}^{*}\right)+q\left(c_{m}-g_{m}-w_{m d}\right)}{Q_{s c}^{*}-S\left(Q_{s c}^{*}\right)} \\
(1-\delta) \geq \frac{q}{Q_{s c}^{*}} \\
s_{d}<\beta_{1}<w_{a d}<p \\
s_{a}<\beta_{2}<w_{m a}<w_{a d} \\
\beta_{1}>=\beta_{2}
\end{gathered}
$$

Provided $\left(c_{r}, c_{d}, c_{m}, g_{r}, g_{d}, g_{m}, w_{d r}, w_{m d}, p, \beta_{1}, \beta_{2}, \delta>=0\right)$

For all $i=r, d, m$ and $j={ }^{*} *$ ', ' $B$ ', ' $Q F$ '

Figure 3. The problem formulation for three-level supply chain contracts.

decision variables are the constraint (C.1), which is important to capture the interests of all supply chain members. This method may also help in determining the feasibility of decision variables.

The quantification of the changes in terms of profit functions may help in decision-making regarding the acceptance or rejection of contracts. The value of coordination can be realized if some performance improvement can also be observed by implementing these contracts. By quantifying the improvement required in performance measures, the members may decide different contract parameters.

Based on the formulation of the analytical model in figure 3 , the following points in relation to the quantification of the changes in various performance measures can be noted:

(i) The determination of decision variables of contracts, which are dependent on expected sales.

(ii) The determination of feasible range of decision variables of contracts satisfying all the constraints mentioned in 3 . 
(iii) The comparison of various sub-cases is discussed.

(iv) The percentage improvement in various performance measures with respect to 'No coordination' case to realize the value of coordination.

(v) The analysis of the feasibility of various sub-cases (i.e. under which conditions the contracts are advantageous and when the contracts parameters need to be revised).

The decision variables are required to be evaluated at the two interfaces: manufacturerdistributor interface and distributor-retailer interface. Various iterations are required to simultaneously satisfy the constraints from C. 1 to C.9 presented in figure 3, which increases the complexity in finding the feasible values of contract decision variables.

A number of scenarios have to be generated to capture the complexity of two cases. To generate different scenarios of coordination by contracts, simulation is the one of the most powerful tools. By using simulation, it is possible to generate and test different decisionmaking alternatives upon more possible foreseeable scenarios, in order to ascertain in advance the level of optimality and robustness of a given strategy (Terzi \& Cavalieri 2004). Simulation may be used to capture uncertain demand to evaluate various performance measures under different scenarios of contracts (Arshinder et al 2009). The relations developed in analytical model will be the inputs to simulate various 'what-if' scenarios. A numerical example illustrated in the next section will help SC members to decide that which various scenarios of the contracts will coordinate the SC members.

\subsection{Numerical example}

The proposed methodology can be demonstrated with the help of a numerical example. By using equations (1) to (25), a numerical example is considered and a simulation is carried out for 50 values on an Excel worksheet. A step-by-step approach for the simulation is presented in figure 4.

3.9a Inputs to the simulation: The parameters such as unit marginal cost, wholesale price, salvage, goodwill cost and price of product in monetary units for buyer and supplier are the inputs to the simulation model. The cost and price parameters may be selected based on the fourth assumption of analytical model. The random demand has been generated from normal distribution with specified mean and standard deviation. The case I, 'No coordination case' is considered as a reference point with respect to which the other cases of 'Coordination Case II (with contracts)' are compared. The cost and price data at each member is the input for the model as shown in table 4.

The quantification of performance measures is done for the following scenarios:

3.9b 'No Coordination' case: The optimal order quantity of retailer is determined based on the cost and price parameters of retailer with the help of equation (4).

3.9c 'Coordination case': Sub-case (a): optimal order quantity of supply chain is determined based on the cost and price parameters of manufacturer, distributor and retailer as per the equation (5).

3.9d Sub-case (a) + buyback contracts: The buyback prices are determined by using the inequalities (13), (14) and (15). These inequalities give lower bound and the upper bound of buyback prices. 
Table 4. Input data for the model.

\begin{tabular}{llll}
\hline Manufacturer & \multicolumn{3}{c}{ Retailer } \\
\hline Production cost $\left(c_{m}\right)$ & $: 20$ & Marginal cost $\left(c_{r}\right)$ & $: 5$ \\
Goodwill cost $\left(g_{m}\right)$ & $: 6$ & Goodwill cost $\left(g_{r}\right)$ & $: 8$ \\
Salvage $\left(s_{m}\right)$ & $: 16$ & Salvage $\left(s_{r}\right)$ & $: 28$ \\
Wholesale price $\left(w_{m d}\right)$ & $: 36$ & Price of product $(p)$ & $: 60$ \\
Distributor & & \\
Marginal cost $\left(c_{d}\right)$ & $: 7$ & Demand distribution $N\left(100,20^{2}\right)$ \\
Goodwill cost $\left(g_{d}\right)$ & $: 7$ & The cost and price are in monetary units \\
Salvage $\left(s_{d}\right)$ & $: 17$ & \\
Wholesale price $\left(w_{d r}\right)$ & $: 50$ &
\end{tabular}

3.9e Sub-case (a) + Quantity flexibility contracts: The minimum commitment by the retailer for the order quantity can be determined by using inequality (25).

3.9f Output of the simulation model: The following are the performance measures evaluated in each scenario:

Expected profits, Revenues generated, Salvage value, Goodwill cost, Marginal cost, Wholesale value, Expected sales, Left over units, Units short.

The above performance measures are evaluated for all scenarios, which are compared with the 'no coordination' case to impress the importance of coordination by contracts. The performance measures so chosen on which the profit function of all SC members are dependent. By introducing sub-cases there can be improvement in some of the performance measures and at the same time some performance measures will be reduced. The combined effect on the expected profits can be quantified by simulation, and this quantification of expected profits only is not sufficient. The study of the impact of various sub-cases on each performance measure will present clear picture of significance of coordination mechanisms, which is required to be tackled by simulation.

\section{Results and discussion}

The results of simulation are presented in the table 5. The inequalities (12), (13), (14), (15) and (25) of analytical model presents the bounds for the decision variables of contracts. The inequalities are derived based on the basic premise that the members will encourage contracts if the profits are more in coordination case compared to the independent case.

For the numerical example under consideration, the total supply chain profits are more in the case II, the case of coordination by contracts than case I. The other performance measures are also improved by contracts. It is interesting to note that individual profits are also increased in case of coordination by contracts. The optimal order quantity of whole SC reduces the profits of retailer. The contracts act as cushion against the reduction of profits. Also, the manufacturer and distributor generate more profits by encouraging retailer to order more quantity.

The profit functions of retailer and distributor are improved with increase in the buyback price $\beta_{1}$ and $\beta_{2}$ respectively. Although, the analytical model gives some range or bounds for $\beta_{1}$ and $\beta_{2}$, the whole range may not be beneficial for all the supply chain members. The simulation of numerical example helps in determining the values of $\beta_{1}$ and $\beta_{2}$ which improves the expected profits of all supply chain members from case I. Similarly, the relation for flexibility provided to the retailer $\delta$ gives the lower bound of minimum commitment of 


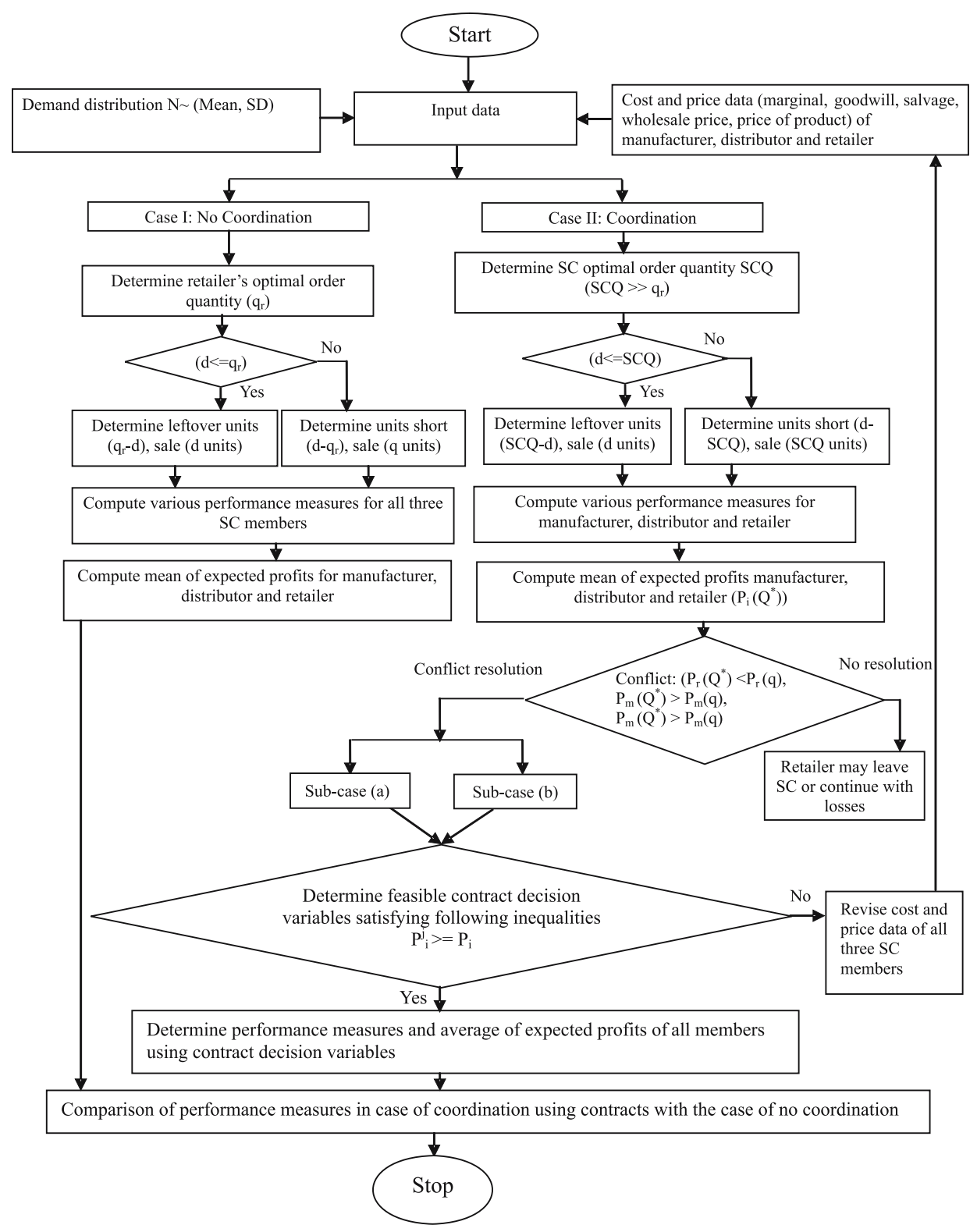

Figure 4. A step-by-step approach for simulating the coordination cases of three-level supply chain.

order quantity. The simulation provides the value of $\delta$, which improves the profit function of all SC members by satisfying all the constraints presented in formulation.

The values of different contract parameters are: $\beta_{1}=46, \beta_{2}=26$ and $\delta=0.7064$. Any member will continue to remain as a part of the supply chain till the profits in case of contracts are more than the profits in the independent case. The improvement in the performance by using the contract parameters is due to the price flexibility $\left(\beta_{1}\right.$ and $\left.\beta_{2}\right)$ given in case of buyback contract and the quantity flexibility $\left(\delta Q_{s c}^{*}\right)$ given in case of quantity flexibility contract. 


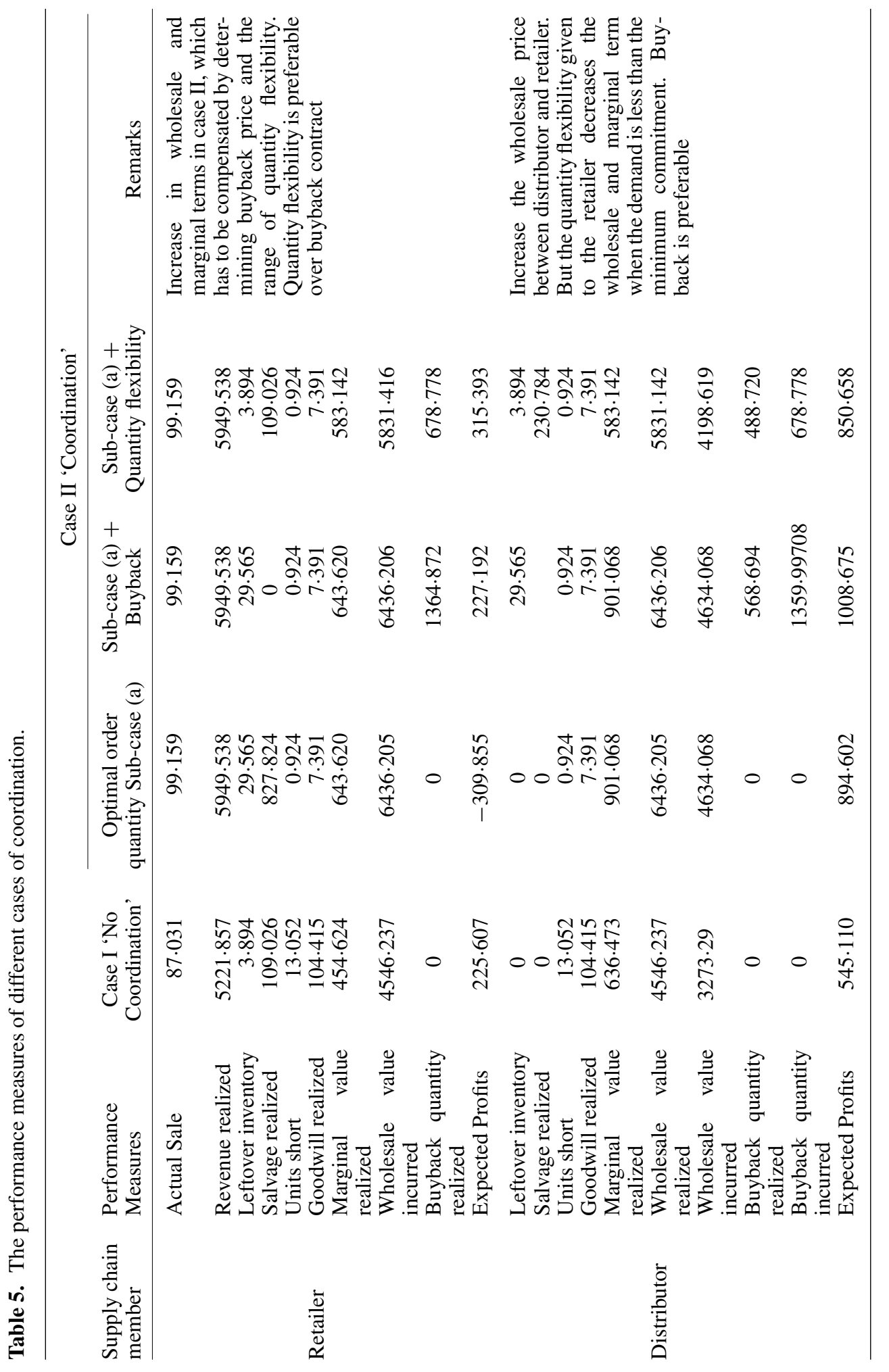




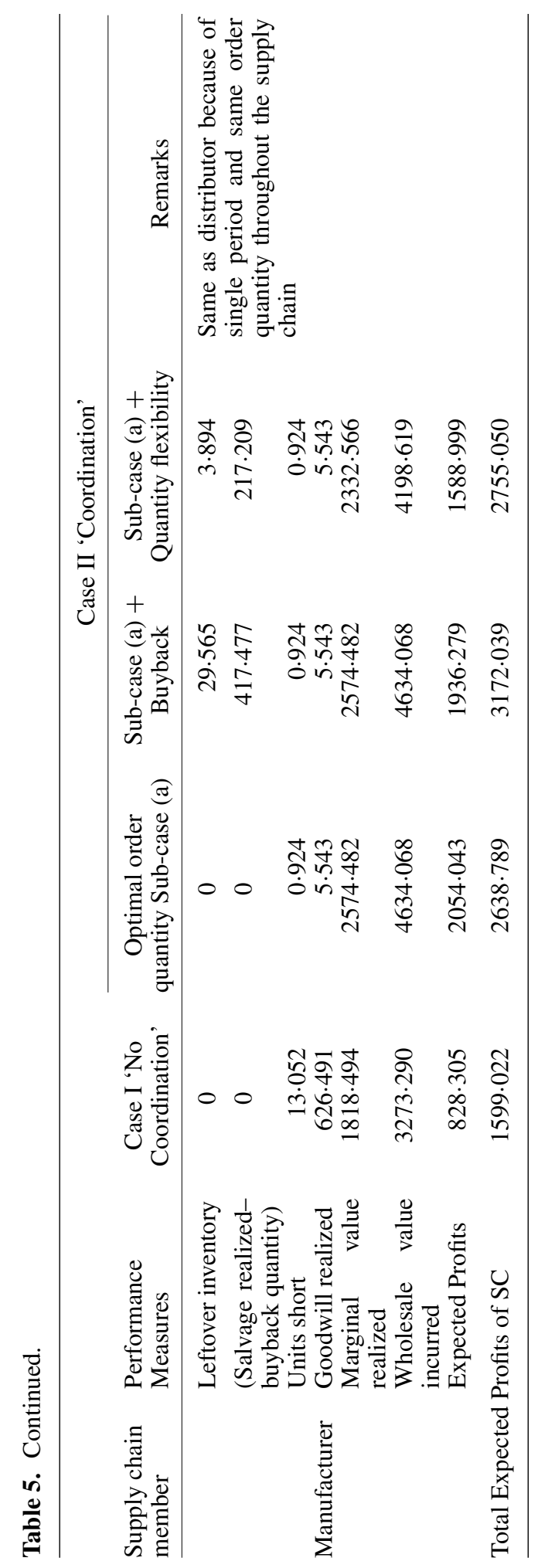


The performance measures in terms of number of units such as average sales, units short and leftover units would result same in the cases: sub-case (a), sub-case (a) + buyback, subcase (a) + quantity flexibility if the SC members agree to order optimal order quantity of supply chain. In case I ('No Coordination'), the average sales for retailer is lesser than in case II. This is due to the increase in order quantity, which fulfill more demand at retailer and hence reduce the stockouts from 13.052 (in case I) to 0.924 (in case II).

The increase in order quantity in case II results in more leftover units. This increase in losses due to more number of leftover units can be deviated by offering contracts. The buyback contracts helps in sharing some losses due to leftover units among SC members, where downstream member returns the leftover units at buyback price to upstream SC member at the end of period. The quantity flexibility contracts will help in compensating the retailer for losses when demand lies between minimum commitment and maximum commitment of order quantity. It can also be observed from the new performance measure buyback realized. In buyback contracts, the upstream members share risk of all the unsold units at retailer at the end of period. Whereas, in quantity flexibility contracts the risks are shared among SC members only when retailer orders the quantity more than the minimum commitment. Even though the risk sharing among SC members is more in buyback contracts due to leftover units, the quantity flexibility contracts help in improving the expected profits of retailer due to decrease in wholesale incurred and marginal cost incurred at retailer. The reverse is observable at manufacturer and distributor.

The quantity flexibility contract helps in reducing the units short and improving the average sales with no impact on leftover inventory. There is a scope to design contracts in which the leftover inventory could be an item for negations while drafting the contracts. The marginal term and the wholesale term are linearly dependent on order quantity. The increase in these terms improves the profits of manufacturer and distributor but reduce the profits of retailer.

It is observed that the difference in revenue term from the 'No Coordination' case is more than the other cost terms. Hence, more the revenues generated more is the value of coordination between supply chain members.

The flexibility can be realized in the above contracts are mentioned below.

\subsection{Buyback contract}

The price of unsold goods can be returned at a price more than the retailer/distributor salvage. The difference between buyback price and the salvage value per unit (price flexibility) is the profit improvement of retailer and the increase in order quantity improves the performance of distributor/manufacturer (as the case may be). Hence, this type of contract may provide a cushion against under stock.

\subsection{Quantity flexibility contract}

Some flexibility in order quantity is provided to the retailer/distributor, which help in reducing the marginal costs and wholesale prices. The range of quantity flexibility is the difference between minimum commitment of order quantity by the retailer/distributor and the maximum quantity committed to deliver by distributor/manufacturer.

The value of coordination can be realized in the form of performance improvement and the flexibility in terms of price and quantity. It can be explained by taking an example of performance measures (in number of units) of retailer, which contributes to increase in the profit equation of retailer. The contribution in increasing performance is $24 \%$ in average sales, $24 \%$ in units short and $52 \%$ increase in the value realized on account of left over inventory at the new buyback price for the retailer. 


\subsection{Observations on different cases of coordination}

Supply chains with reduced profit margins, intensive competition, pressure for keeping low inventory and huge cost associated with capacities, coordination becomes imperative. The proposed analytical model on supply chain contracts helps in coordinating supply chain members with following observations:

- Applicability of coordination elements is justified in different cases of coordination, which can be observed in terms of improving performance measures. The equation (4) helps in determining the coherent order quantity of supply chain. The mutuality in supply chain can be achieved by using inequality (9). With this inequality the decision variables of contracts are so determined to improve the profits of all the supply chain members from the case I.

- The model can be simulated to quantify the performance measures such as revenues realized, buyback realized, wholesale price realized etc. The various 'what-if' scenarios in simulation may also help in realizing the importance of all elements of coordination. The what-if scenarios like the effect of changing cost or price parameters on the decision variables of contracts can be analysed. The feasible range of buyback contracts are dependent on the cost and price structure considered by all supply chain members. The amount of flexibility provided to downstream members can be changed by changing cost and price data.

- The performance measures defined in optimal case may reduce the computational complexity. It can be observed from the tables 3 and 4 that some of the performance measures do not change in the cases of sub-case (a) + buyback contracts and sub-case (a) + quantity flexibility contracts with respect to. optimal case (only sub-case (a)) in coordination case II. This is the advantage of finding $Q_{s c}^{*}$ first followed by contract decision variables.

- It can be observed that for same kind of demand, the quantity flexibility contracts are more beneficial over buyback contracts, as the retailer can change the order and the distributor/manufacturer (table 3 ) give full credit for the leftover inventory.

- A collective performance measure of coordinated supply chain can be proposed on the basis of various improving performance measures due to contracts. The collective performance measure may present an extent for coordination by contracts. One of the methodologies can be graph-theoretic approach as discussed by Kaur et al (2006).

- The implementation of all three elements of coordination helps in removing dominance of a single player in supply chain. The members are encouraged to take coherent and mutual decision-making.

\subsection{Utility of the proposed model}

Typically, organizations complement each other in supply chain. Interdependencies may enhance such complementarities. Coordination could also be a source of competitive advantage.

The other implications of the proposed framework for practicing managers are as follows:

- The model can be a decision-making tool which will help in taking coherent and mutual decisions prior to the realization of actual demand, as demonstrated with the help of numerical example. It may also help in handling some exceptions, which may arise in future by joint decision making. 
- The same model can be compared with two-level supply chains and compared with higher number of levels in supply chain. The determination of decision variables becomes difficult with increase in the number of levels.

- The proposed framework is a simple-to-use and easy-to-implement approach to model the supply chain contracts based on the extension of newsboy model.

- In quantity flexible contracts, the manufacturer should have sufficient capacity to provide flexibility of order quantity to the distributor/retailer

- This model will also help in formulating the situation when intermediate member of a three-level supply chain can be bypassed to a two-level supply chain. The behaviour of performance measures of two-level supply chain may be similar to the three-level supply chain discussed, but the magnitude of performance measures will be different. The cost and price data of intermediate member, had he been present, would have increased the SCQ. This increase in SCQ can be saved and savings can be shared by devising some mutually beneficial mechanism.

- The various 'what-if' scenarios of the proposed model may help managers to face uncertain situations. The scenarios can be generated for different demands and compared. It helps in selecting the best case handling particular type of demand condition.

- The applicability of coordination elements in supply chain contracts may lead to stronger relationship between supply chain members with trust and commitment. The mutual and coherent decisions may result in long-term relationships.

- The various performance measures of coordinated supply chain may also help in evaluating and selecting supply chain members. The supply chain members may evaluate various performance measures in advance before designing contracts with the potential $\mathrm{SC}$ member based on the proposed cost and price data.

\section{Concluding remarks}

An effort has been made in this paper to apply coordination theory in supply chain contracts. The coordination elements help in coherent decision making in whole supply chain, mutual sharing of risks and rewards and keep all the members motivated to form partnership. An analytical model is proposed for two types of contracts: buyback and quantity flexibility in three-type supply chain. The model justifies the elements of coordination i.e. coherent decision-making by having common order quantity $Q_{s c}^{*}$ and mutual decision making by deciding the decision variables of contracts so that the profits of all members in case of contracts are greater than the case of no coordination. It has been demonstrated that various performance measures can be improved by adopting contracts. The absence of any element of coordination out of three elements may lead to dominance in supply chain, which is not desirable in coordinated supply chain.

This model is an extension of classical newsboy model, which can be applied to not only newspaper or books industry but can be utilized for other products like pharmaceutical, auto components and perishable products. The model is applicable to single-period but it can also be extended to multi-period, where the type of product or the relationship between SC members shows some peculiarity. One of the examples can be of products, which have limited shelf life like perishable products and pharmaceuticals. These products are ordered frequently, but because of the shelf life, the buyback contracts may be used to reduce the losses due to leftover inventory at the downstream member.

There are a number of other coordination mechanisms, which may help in coordinating the supply chain members. These coordination mechanisms are very important to coordinate all 
the process and activities of supply chain (Arshinder et al 2007). The supply chain contract may also present the scope for other mechanisms or the contracts can be adopted in conjunction of following mechanisms:

- Information sharing: The supply chain members need to share information regarding the cost and price parameters, so that a coherent decision regarding order quantity can be taken. Also, the information on leftover units, average sales and units short at the end of period should be shared by the retailer to other upstream members. The demand is assumed known and shared at each member in the present model. If the demand information is not shared, there may be reduction in the profit function of members.

- Joint decision-making: The supply chain members jointly calculate the coherent order quantity. The joint decision-making regarding the contract decision variables may be done in such a way so that to plan the duration of contract and to control the contract decision variables.

- Information technology: The information technology plays an important role in transferring information among supply chain members. For example in the quantity flexibility contract, the distributor shares revised demand near to the selling season. This information has to be transferred in less time so that the revised demand can be met in time. This mechanism helps in transferring data as the number of levels goes on increasing in supply chain.

- Profit sharing: The supply chain members may design a suitable mechanism to share the total profits improved by achieving coordination. One of the mechanisms may be the sharing of total profits in proportion to the value addition at particular member.

In the model, it is assumed that an optimal order quantity is unique for whole supply chain. This case may differ when a different set of levels of supply chain are considered. For example, if an assembler or raw material supplier is also introduced, then proper mechanism has to be devised to determine the optimal order quantity. It depends on the number of the components in a product. So, the feasibility of the model has to be checked with respect to the number of levels in the supply chain.

There is a feasible range for the decision variables of contracts. Beyond the feasibility range, the price data has to be revised at each level of supply chain.

\section{References}

Arshinder, Kanda A, Deshmukh S G 2006 Coordination based perspective on the procurement process in supply chain. Int. J. Value Chain Management 1: 117-138

Arshinder, Kanda A, Deshmukh S G 2007 Supply chain coordination issues: A SAP-LAP framework. Asia Pacific Journal of Marketing and Logistics 9: 240-264

Arshinder, Kanda A, Deshmukh S G 2008 Supply chain coordination: Perspectives, empirical studies and research directions. Int. J. Production Econo. 115: 316-335

Arshinder, Kanda A, Deshmukh S G 2009 A framework for evaluation of coordination by contracts: A case of two-level supply chains. Computers and Industrial Eng. 56: 1177-1191

Atkinson A A 1979 Incentives, uncertainty, and risk in news-boy problem. Decision Science 10: 341-353

Barbarosoglu G 2000 An integrated supplier-buyer model for improving supply chain coordination. Production Planning and Control 11: 732-741

Barnes-Schuster D, Bassok Y, Anupindi R 2002 Coordination and flexibility in supply contracts with options. Manufacturing and Service Operations Management 4: 171-207 
Bose I, Anand P 2007 On returns policies with exogenous price. European J. Operational Res. 178: $782-788$

Cachon G P 2004 Supply chain coordination with contracts, In S Graves, T de Kok (eds.), Handbooks in Operations Research and Management Science. North Holland Press

Cachon G P, Lariviere M A 2005 Supply chain coordination with revenue sharing contracts: strengths and limitations. Management Science 51: 30-44

Campbell A J 1997 What affects expectations of mutuality in business relationships? J. Marketing Theory and Practice 5: 1-11

Chaib-Draa B, Moulin B, Mandiau R, Millot P 2004 Trends in distributed artificial intelligence. Artificial Intelligence Rev. 6: 35-66

Chaudhary A, Deng P, Rathnam S 1996 A computational model of coordination. IEEE Transactions On Systems Man and Cybernetics - Part A: Systems and Humans 26: 132-141

Chauhan S S, Proth J M 2005 Analysis of a supply chain partnership with revenue sharing. Int. J. Production Economics 97: 44-51

Chen H, Chen J, Chen Y F 2006 A coordination mechanism for a supply chain with demand information updating. Int. J. Production Economics 103: 347-361

Emmons H, Gilbert S M 1998 Note. The role of returns policies in pricing and inventory decisions for catalogue goods. Management Science 44: 276-283

Giannoccaro I, Pontrandolfo P 2004 Supply chain coordination by revenue sharing contracts. Int. J. Production Economics 89: 131-139

He J, Chin K S, Yang J B, Zhu D L 2006 Return policy model of supply chain management for single-period products. J. Optimization Theory and Applications 129: 293-308

Kaur A, Kanda A, Deshmukh S G 2006 A graph theoretic approach for supply chain coordination. Int. J. Logistics and System Management 2: 321-341

Kim T, Hong Y, Lee J 2005 Joint economic production allocation and ordering policies in a supply chain consisting of multiple plants and a single retailer. Int. J. Production Res. 17: 3619-3632

Koulamas C 2006 A newsvendor problem with revenue sharing and channel coordination. Decision Sciences 37: 91-100

Krishnan H, Kapuscinski R, Butz D A 2004 Coordinating contracts for decentralized supply chains with retailer promotional effort. Management Science 50: 48-63

Lee C H, Rhee B D 2007 Channel coordination using product returns for a supply chain with stochastic salvage capacity. European J. Operational Res. 177: 214-238

Malone T, Crowston K 1994 The interdisciplinary study of coordination. ACM Computing Surveys 26: $87-119$

McCann J E, Ferry D L 1979 An approach for assessing and managing interunit interdependence Academy of Management Rev. 4: 113-119

Milner J M, Rosenblatt M J 2002 Flexible supply contracts for short life cycle goods: The buyer's perspective. Naval Research Logistics 49: 25-45

Mintzberg H 1979 The structuring of organizations. Englewood Cliffs, Prentice Hall

Nahmias S, Smith S A 1994 Optimizing inventory levels in a two-echelon retailer system with partial lost sales. Management Science 40: 582-596

Padmanabhan V, Png I P L 1997 Manufacturer's returns policies and retail competition. Marketing Science 16: 81-94

Pasternack B A 1985 Optimal pricing and return policies for perishable commodities. Marketing Science 4: 166-176

Rubin P A, Benton W C 2003 A generalized framework for quantity discount pricing schedules. Decision Sciences 34: 173-188

Sethi S P, Yan H, Zhang H 2004 Quantity flexibility contracts: optimal decisions with information updates. Decision Sciences 35: 691-712

Simatupang T M, Wright A C, Sridharan R 2002 The knowledge of coordination for supply chain integration. Business Process Management Journal 8: 289-308 
Terzi S, Cavalieri S 2004 Simulation in the supply chain context: A survey. Computer in Industry 53: $3-16$

Tsay A A, Lovejoy W S 1999 Quantity flexibility contracts and supply chain performance. Manufacturing and Service Operations Management 1: 89-111

Weng Z K 2004 Coordinating order quantities between the manufacturer and the buyer: A generalized newsvendor model. European J. Operational Res. 156: 148-161

Whang S 1995 Coordination in operations: taxonomy. J. Operations Management 12: 413-422

Yang S, Yang J, Abdel Malek L 2007 Sourcing with random yields and stochastic demand: A newsvendor approach. Computers and Operations Research 34: 3682-3690

Yao D, Yue X, Wang X, Liu J J 2005 The impact of information sharing on a returns policy with the addition of a direct channel. Int. J. Production Economics 97: 196-209

Yao Z, Leung S C H, Lai K K 2008 Manufacturer's revenue sharing contract and retail competition. European J. Operational Res. 186: 637-651

Yue X, Raghunathan S 2007 The impacts of the full returns policy on a supply chain with information asymmetry. European J. Operational Res. 180: 630-647

Zou X, Pokharel S, Piplani R 2008 A two-period supply contract model for a decentralized assembly system. European J. Operational Res. 187: 257-274 